\title{
The influence of temperature on the differential current protection of EHV shunt capacitor bridges
}

\author{
LIU Yang ${ }^{1, a}$, WANG Ziqi ${ }^{2, b}$, MA Yong ${ }^{1, \mathrm{c}}$, XIE Tianxi ${ }^{1, \mathrm{~d}}$, ZHOU Zhicheng ${ }^{1, \mathrm{e}}$, \\ CHEN Guang ${ }^{1, f}$ \\ ${ }^{1}$ Jiangsu Electric Power Company Research Institute, Nanjing 211103, China; \\ ${ }^{2}$ School of Electrical Engineering, Beijing Jiaotong University, Beijing 100044, China. \\ aleon00531@163.com, ${ }^{\mathrm{b}} 14117390 @$ bjtu.edu.cn, ' $\mathrm{cma.y@foxmail.com,} \mathrm{dspone@foxmail.com,} \mathrm{,}$ \\ esimencola@qq.com, , tanzhongtan@163.com,
}

Keywords: temperature, fuse, double bridge differential current protection, shunt capacitor, setting calculation

\begin{abstract}
The shunt capacitor is a very important part of the EHV (Extra High Voltage) transmission system in China. Shunt capacitors can compensate reactive power and improve the power quality. It plays an important role in the regulations of voltages and power factors. At the same time, high repairing rates are always found in the outlet terminal shunt capacitors in each EHV station. Therefore, the protection scheme for EHV shunt capacitor is widely used: a single capacitor fuse protection acts as the primary protection, and the double bridge differential current protection acts as the backup protection. However, most of the existing research is based on the analysis of different fault conditions. The discussions on external factors, such as temperature, are limited. This paper studies the influences from temperature variations on the double bridge differential current protection of shunt capacitors. The influences are demonstrated by theoretical calculations as well as simulations.
\end{abstract}

\section{Introduction}

EHV (Extra High Voltage) shunt capacitor is an important equipment in EHV system. Due to the impact of EHV system over voltage and inrush current, the failure rate of shunt capacitors is high among all power system components. Since the shunt capacitor protection is very important for the safety of the whole system, a lot of research has been carried out in this area.

In order to protect the capacitor unit, reference [3] analyzes the principle of internal and external fuse protections and the protection coordination. Reference [4] discussed the applying conditions of inside and outside fuse protections.

In view of the overall protection of capacitor groups, reference [5] presents an open-delta voltage differential protection, and its calculation methods under different connections. According to the errors of capacitance, the unbalance of three-phase voltages and other factors, reference [6] proposed an unbalance value estimation method for open-delta voltage protection, phase voltage protection and current differential protection. Reference [7] analyzes the practical situations of the protection for EHV Changzhi Railway Station.

This paper analyzes the practical operation of EHV station capacitors. The EHV station capacitor group protection is more common for the fuse protection with the use of double bridge differential current protection. This paper also analyzes the current variations caused by the external temperatures, especially the relationship between temperatures and capacitance. The influences from temperatures on EHV shunt capacitor double bridge differential current protection is analyzed theoretically and verified by simulations of practical systems. Considering the influence of temperature on the EHV shunt capacitor double bridge differential current protection can make the setting of protection much closer to the actual situation, which has practical significance for engineering practice. 


\section{EHV shunt capacitor protection method}

EHV substation mainly adopts a large series of capacitors to provide reactive power compensation. Because of the factor of this large capacity, the protection configuration generally uses internal fuse protection as the main protection as well as double differential current protection as the back-up protection. The two kinds of protection modes fit with each other through the mutually matched way.

Internal fuse protection. Every capacitor element is connected with a internal fuse. When the capacitor is broken down by the short circuit, the current will increase rapidly, and the other intact components in the same string combined section will discharge large current. Large current will make the internal fuse fuse rapidly to isolate the fault component.

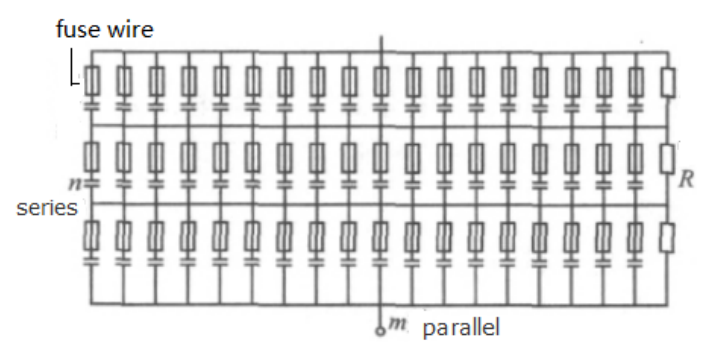

Fig. 1 internal fuse protection

Double bridge unbalance current protection. Fuse protection acts to cut the faulty components off due to the breakdown of the capacitor. The whole bridge capacitor will appear uneven distribution, resulting in unbalanced current in the bridge between the arms. Double bridge differential current protection uses the unbalanced current between the bridge arms, by considering the voltage value of a capacitor series section as well as calculating the maximum number of the broken-down elements, to result in differential protection action current value. When the unbalanced current is lager than the action value, the relay protection device will act rapidly to cut the whole group of capacitors off.

In practical application, coordination between fuse protection and the setting value of double bridge differential protection are often affected by a series of external conditions. Temperature has a direct effect on the capacitance, which will further affect the protection. This paper considers the influence of external factors - temperature to analyze double bridge EHV shunt capacitor differential current protection.

\section{The influence of temperature on the parameters of capacitor}

In general, people pay more attention to the rated capacity and the the value of permissible voltage of the capacitor. They often ignore the effects made by temperature. In practical application, the capacitance parameters are closely related to temperature. Especially the temperature has great difference in different environment, which will make capacitance change a lot. Capacitance temperature coefficient refers to " within a given interval, when temperature changes every 1 degrees, the ratio between the changes in the capacitance value and the nominal capacitance ."

$$
\alpha_{c}=\frac{1}{C} \cdot \frac{\Delta C}{\Delta t} \times 10^{-6}
$$

$\alpha_{c}$ refers to temperature coefficient. $\Delta C_{\text {refers to differential capacitance measured in room }}$ temperature and extreme temperature. $\Delta t$ refers to the difference between room temperature and extreme temperature.

With the actual temperature of $\mathrm{t}^{\circ} \mathrm{C}$, the capacitance can be calculated by the following equation:

$$
C_{t^{\circ} \mathrm{C}}=\left(\alpha_{c} \cdot \Delta t+1\right) C_{\text {tnormal }}{ }^{\circ} \mathrm{C}
$$




\section{Calculation for the coordination of fuse protection and double bridge differential current protection considering the effect of temperature}

Due to the influence of temperature, for the practical high voltage capacitor, high temperature can reduce capacitance, which results in the bridge arm current increasing. At the same time, Fuse wire can be more easily to fuse because of the high temperature. Therefore, considering the influence of temperature, the calculation mainly talks about the condition which fusing occurs at one bridge arm in high temperature.

When fuse protection acts, other intact components in the same series section is much more likely to breakdown. This scheme focus on one series section.

Theoretical calculation formula. Double bridge differential protection wiring structure is often used as Fig.2 :

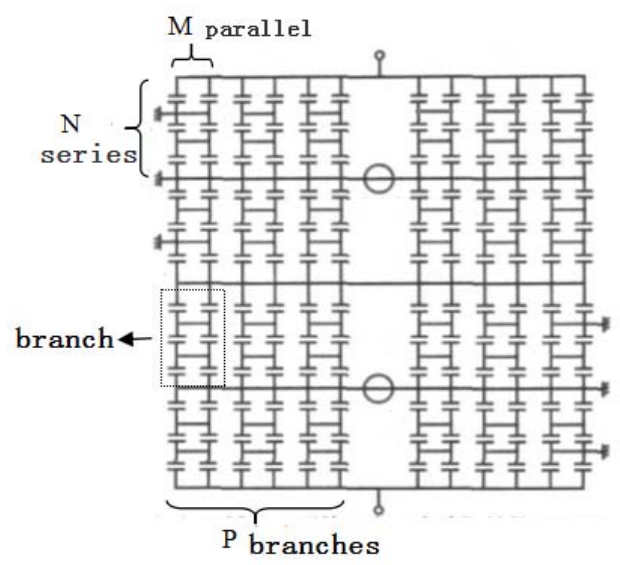

Fig. 2 Double bridge differential protection wiring structure

This paper take the condition that the internal components in a single capacitor takes the structure of $\mathrm{m}$ parallel with $\mathrm{n}$ series and a capacitor takes the structure of $\mathrm{M}$ parallels $\mathrm{N}$ series on $\mathrm{P}$ branches, We can let the capacitance of one capacitor components be $\mathrm{Ce}$, the capacitance of one capacitor components in high temperature be $\mathrm{Ce} 1$ and removal number of fault components in an element series section be $\mathrm{k}$.

On the basis of conventional mathematical derivation, we can get:

The capacitance of a single capacitor

$C_{n}=\frac{m}{n} C_{e}$

The capacitance of a faulty capacitor in high temperature

$C_{n}^{\prime}=\frac{1}{\frac{1}{(m-k) C_{e 1}}+\frac{n-1}{m C_{e 1}}}=\frac{m(m-k)}{n(m-k)+k} C_{e 1}$

Normal capacitance of one arm

$C_{b}=\frac{C_{e} \cdot m}{n} \cdot \frac{M \cdot P}{N}$

Capacitance of faulty bridge in high temperature

$C_{b}^{\prime}=C_{z}^{\prime}+(P-1) \cdot C_{z}=C_{z}^{\prime}+(P-1) \cdot \frac{C_{n} \cdot M}{N}$

Use the capacitance change rate defined in lecture [2] 


$$
\begin{aligned}
& \beta_{b}=\frac{C_{b}^{\prime}-C_{b}}{C_{b}}=\frac{\left\{\frac{[M n(m-k)+(M-1) k] \cdot N}{[N M n(m-k)+(M N-N+1) k]}+(p-1)\right\} C_{e 1}}{P C_{e}}-1= \\
& \frac{\left\{\frac{[M n(m-k)+(M-1) k] \cdot N}{[N M n(m-k)+(M N-N+1) k]}+(P-1)\right\}\left(\alpha_{c} \Delta t_{1}+1\right)}{P\left(\alpha_{c} \Delta t+1\right)}-1
\end{aligned}
$$

Current change in one arm in high temperature

$$
\Delta I_{b}=\beta_{b} I_{b}=\frac{\beta_{b} w C_{b} U_{e x}}{4}
$$

considering unbalance current

$$
\begin{aligned}
& I=\frac{1}{2} \Delta I_{b}=\frac{\beta_{b} w C_{b} U_{e x}}{8} \\
& =\frac{\frac{[M n(m-k)+(M-1) k] \cdot N}{[N M n(m-k)+(M N-N+1) k]}+(P-1)}{8 n N\left(\alpha_{c} \Delta t+1\right)} \cdot w C_{e} m M U_{e x}\left(\alpha_{c} \Delta t_{1}+1\right)-\frac{w C_{e} m M P U_{e x}}{8 N n}
\end{aligned}
$$

Without considering temperature, namely $\triangle \mathrm{t}$ is the same with $\triangle \mathrm{t} 1$ :

$$
I=\frac{\frac{[M n(m-k)+(M-1) k] \cdot N}{[N M n(m-k)+(M N-N+1) k]}+(P-1)}{8 n N} \cdot w C_{e} m M U_{e x}-\frac{w C_{e} m M P U_{e x}}{8 N n}
$$

Because the fault occurs on the arm in high temperature, namely $\triangle \mathrm{t} 1$ is larger than $\triangle \mathrm{t}, \quad(a \triangle$ $\mathrm{t} 1+1$ ) is larger than ( a $\triangle \mathrm{t}+1$ ) obviously.

\begin{tabular}{|c|c|c|c|}
\hline $\begin{array}{l}\text { Single } \\
\text { rated } \\
\text { capacity } \\
\text { Qc(kvar) }\end{array}$ & $\begin{array}{c}\text { Single rated } \\
\text { voltage } \\
\mathrm{Ue}(\mathrm{kV})\end{array}$ & $\begin{array}{c}\text { Single rated } \\
\text { capacitance } \\
\mathrm{C}(\mu \mathrm{F})\end{array}$ & $\begin{array}{c}\text { Single rated } \\
\text { current } \\
\text { Ice }(\mathrm{A})\end{array}$ \\
\hline 486.2 & 6.077 & 41.907 & 80.007 \\
\hline $\begin{array}{c}\text { Reactanc } \\
\text { e rate } \\
\text { A }\end{array}$ & $\begin{array}{c}\text { Current } \\
\text { transformer } \\
\text { ratio } \\
\mathrm{T}\end{array}$ & $\begin{array}{l}\text { The number } \\
\text { of single } \\
\text { elements in } \\
\text { parallel } \\
\text { m }\end{array}$ & $\begin{array}{c}\text { The number } \\
\text { of elements } \\
\text { in series } \\
n\end{array}$ \\
\hline 0.05 & 3 & 14 & 3 \\
\hline
\end{tabular}

It can be seen through the above theoretical analysis that the introduction of temperature causes the increasing of the unbalanced current value.

Validation of practical simulation model. The simulation platform adopts double bridge unbalance current protection mode with the data of $1000 \mathrm{KV}$ substation $110 \mathrm{KV}$ outlet side capacitor. The actual parameters of Siyuan capacitor are listed as Table 1.

The simulation model uses the actual parameters of Siyuan capacitor.It takes the structure of 2 parallel 3 series on 3 branch with capacitor unit temperature coefficient $-4.3 \times 10-4$.

In normal temperature $\left(25^{\circ} \mathrm{C}\right)$, the single capacitor rates capacitance $41.907 \mathrm{uF}$. One-degree increase in the temperature causes 4.3/10000-decreasing of capacitance. The capacitance in different temperature can be list as follow: 
Table 2 capacitance in different temperature

\begin{tabular}{ccc}
\hline $\begin{array}{c}\text { temperatu } \\
\text { re }\end{array}$ & $\begin{array}{c}\text { Capacitor } \\
(\mathrm{uF})\end{array}$ & $\begin{array}{c}\text { Arm } \\
(\mathrm{uF})\end{array}$ \\
\hline $23^{\circ} \mathrm{C}$ & 41.943 & 83.886 \\
$24^{\circ} \mathrm{C}$ & 41.925 & 83.850 \\
$25^{\circ} \mathrm{C}$ & 41.907 & 83.814 \\
$26{ }^{\circ} \mathrm{C}$ & 41.889 & 83.778 \\
$27{ }^{\circ} \mathrm{C}$ & 41.871 & 83.742 \\
$28^{\circ} \mathrm{C}$ & 41.853 & 83.706 \\
$29^{\circ} \mathrm{C}$ & 41.835 & 83.670 \\
$30^{\circ} \mathrm{C}$ & 41.817 & 83.634 \\
$31^{\circ} \mathrm{C}$ & 41.799 & 83.598 \\
$32^{\circ} \mathrm{C}$ & 41.781 & 83.562 \\
$33{ }^{\circ} \mathrm{C}$ & 41.763 & 83.526 \\
$34^{\circ} \mathrm{C}$ & 41.745 & 83.490 \\
\hline
\end{tabular}

We can use $30{ }^{\circ} \mathrm{C}$ as the temperature of the faulty arm and the normal temperature is $25^{\circ} \mathrm{C}$. The simulation model can be constructed as Fig. 3.

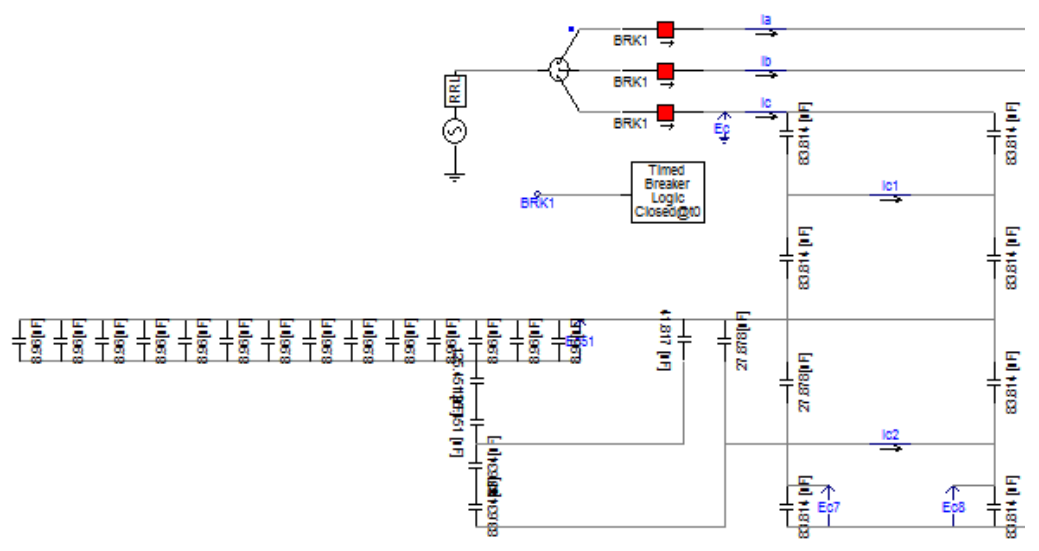

Fig. 3 simulation model

Measure the unbalanced current when fuse protection acts and trips different number of capacitor. Comparison of calculation and simulation. Take the structure of 2 parallel 3 series on 3 branch with capacitor unit temperature coefficient $-4.3 \times 10-4$.

Results can be got when we put the data into the formula under this condition:

$\beta_{b}=\frac{(756-43 k) \times 0.99785}{(756-42 k)}-1$

The unbalance current equals to:

$I=\frac{1}{2} \Delta I_{b}=\frac{\beta_{b} w C_{b} U_{e x}}{8}$

Calculation results and PSCAD simulation results are shown as Table 3: 
Table 3 The unbalanced current calculation results and PSCAD simulation results

\begin{tabular}{cccc}
\hline $\begin{array}{c}\text { The } \\
\text { number } \\
\text { of fuse }\end{array}$ & $\beta \mathrm{b}$ & $\begin{array}{c}\text { Calculation } \\
\text { result (A) }\end{array}$ & $\begin{array}{c}\text { simulation } \\
\text { result (A) }\end{array}$ \\
\hline 1 & -0.0035 & 0.74 & 0.7417 \\
2 & -0.0051 & 1.07 & 1.0712 \\
3 & -0.0069 & 1.44 & 1.4452 \\
4 & -0.0089 & 1.86 & 1.8590 \\
5 & -0.0113 & 2.36 & 2.3681 \\
6 & -0.0140 & 2.94 & 2.9467 \\
7 & -0.0173 & 3.61 & 3.6321 \\
\hline
\end{tabular}

Experimental data can be a good proof of the formula above.

In the above calculation, if all arms are in the same temperature, data can be obtained without considering temperature. Compare different conditions of temperature:

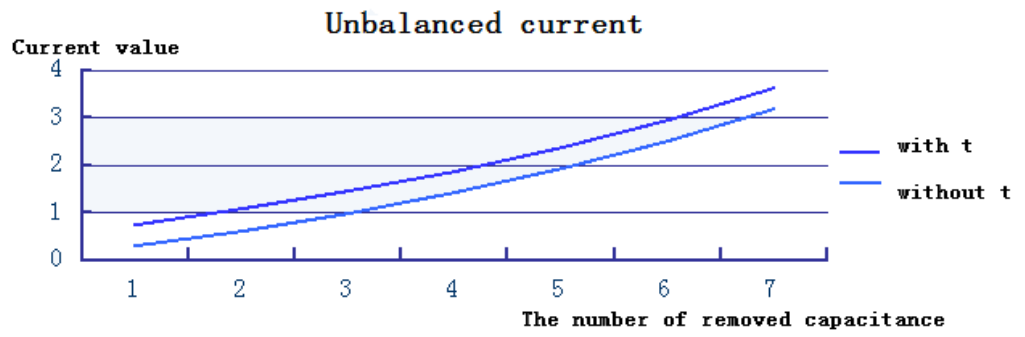

Fig. 4 Unbalanced current

It can be seen that the introduction of temperature has effect on the differential current. We can consider the actual situation. Due to the temperature characteristics of the capacitors, capacitance reduce when temperature rise. Bridge capacitor has further decreased when fuse protection cuts fault components off, resulting in unbalanced current increasing. The formula above is consistent with the actual situation. The effect of temperature should be considered in bridge differential current protection.

\section{Summary}

In the EHV substation, EHV shunt capacitor device is setting in the frame structure. Every single capacitor equipment can be affected by temperature due to the different installation position. The temperature of capacitors operating in the direct sunlight are higher than others. Temperature factor leads to larger unbalanced current. Therefore, the influence on shunt capacitor device double bridge differential current protection cased by temperature should be considered.

\section{References}

[1] GB/2001T11024.32 nominal voltage above $1 \mathrm{kV}$ AC power system with parallel capacitor third: shunt capacitor and shunt capacitor protection [S], 2001

[2] Cui Guoqiang, Zhang Peng. 1000KV EHV station bridge application unbalanced protection capacitor bridge. Power capacitor and reactive power compensation, 2012, 33 (2).

[3] Tang Hui. Fuse protection of shunt capacitor. North China electric power technology.

[4] Yang Changxing, Yang Lichuan, Hua Shuirong. High voltage shunt capacitor bank wiring and the selection of protection mode [A]. 2010 transmission annual conference [C].2010.

[5] Sheng Guozhao, Ni Xuefeng. Integrated and internal fuse capacitor unbalance protection calculation [A]. 2010 power transmission annual conference [C].2010 
[6] Yang Changxing, Zhao Qicheng, Yang Lichuan, Ping Xiaoxiang. Shunt capacitor protection is the unbalance value estimation of $[\mathrm{J}]$. power capacitor and reactive power compensation of.2010 (04)

[7] Li Xiaojie, when Weiguang. ChangZhi Railway Station EHV shunt capacitors [A]. 2010 power transmission annual conference [C].2010.

[8] Zhang Xinghai, Zhang Xueqin, Wu Guangning. Study on insulation protection technology of reactive power compensation capacitors [J], High voltage technology 2005,31 (12): 18220

[9] Sheng Xiaowei, Huang mei, Yan Bo. Parallel capacitor unbalance current protection [J]. Relay, 2006,32 (21): 14217

[10] GB/11024.122001 T nominal voltage for shunt capacitor of $1 \mathrm{kV}$ AC power system, first part : performance testing and rating, General safety requirements of installation and operation guide [S], 2001

[11] DL/ T 84022003 high voltage shunt capacitor [S] technology, 2003

[12] Yang Changxing, Wang Min. Sensitive coefficient of the capacitor unbalance protection [J]. power capacitor, 2005 (4): 8211

[13] Sheng Guozhao, Ni Xuefeng, Yan Fei. Reasonable choice for capacitor rated voltage of high voltage shunt capacitor device. The reactive power compensation device, 2007 (1): 21229

[14] Fang Jinlan. Fuse less capacitor technology development and application [J]. Power capacitor and reactive power compensation, 2008,29 (1): 123

[15] Liu Zhenya. China State Grid Corp 110 500kV substation typical specification [M]. Beijing: China power press, 2007 